\author{
경주마의 마사내에서의 악벽에 관한 조사연구 \\ 윤세영 · 김명화 · 이상락 \\ 건국대학교 동물생명과학대학
}

\title{
A Survey on the Stable Vice of Race Horse in Stable
}

Sei Young Yoon, Myeong Hwa Kim and Sang Rak Lee

College of Animal Bioscience \& Technology, Konkuk University

\begin{abstract}
This study was conducted to identify various habits of stable vices and its occurring frequency in racing horses, currently managed in Korea, through categorizing the total 1,386 head of racing horses in Seoul Racing Park into sex, age and years of stabling. Among the 1,386 horses, 524 heads (37.8\%) have shown habits of stable vices and its appearances rate according to each category is as following; While $40.7 \%$ of stallions showed the highest appearances rate of stable vices by sex, it was $50 \%, 44.2 \%$, and $53 \%$ for the age of 2, 6 and 4, respectively by age, it was $41 \%, 40.6 \%$ and $39.1 \%$ for the years of stabling of 2, 4 and 3, respectively. For the appearances rate of individual stable vices, $7.0 \%$ of mares showed the highest appearances rate of 'kicking at walls', $12.9 \%$ of stallions showed 'biting habit' and $5.7 \%$ of castrated horses showed 'weaving' when grouped by sex. According to age, $8.3 \%$, and $6.1 \%$ of horses of age 2 showed 'kicking at walls', 'wind-sucking' and 'pawing', respectively while $4.9 \%$ of horses of age 3 showed 'pawing', $6.4 \%$ of horses of age 4 showed 'kicking at walls', $6.8 \%$ of horses of age 5 showed 'kicking at walls' and 'biting habit' and $8.7 \%$ of horses of age 6 showed 'weaving' and 'biting habit'. By the year of stabling, 6\% of horses for 1 year had 'pawing habit', 7\% og horses for 2 years had 'kicking at walls', 7.4\% of horses for 3 years had 'biting habit' and it was $6.9 \%$ and $10.6 \%$ for 'weaving' for 4 and 5 years of stabling, respectively. In conclusion, the racing horses in Korea seemed to show high rate of appearance rate of stable vices and it is considered to be necessary to improve stable equipments and management skills to reduce the appearance rate of stable vices.
\end{abstract}

(Key words : Age, Racing horse, Sex, Stable vice, Years of stabling)

\section{I. 서 론}

우리나라 경마의 역사는 약 70 여년으로 경마 인구의 증가와 함께 경주마의 두수도 크게 증 가하는 등 비약적으로 발전하였다. 경마 초창 기에는 경주마가 대부분 외국산마로 구성되었 으나 국적이 있는 경주마를 생산하고자 하는 목표의 결과로 국산경주마가 차지하는 비율이 증가하여 2007년 현재 수적으로 외국산마를 능 가하였으며, 더불어 국산 경주마의 질도 매우 높아졌다.
야생이나 방목중인 말들은 자연이나 초지로 부터 스스로 다양한 먹이를 선택하고 또 지속 적으로 섭취한다. 그러나 경주마들은 마방에서 규칙적으로 사양되기 때문에 자유롭게 돌아다 니며 풀을 뜯는 야생의 말이나 방목을 하는 말 들과는 행동에 있어 차이가 있다. 마방에서 사 육되는 말들에 있어서 이러한 행동의 제약이 종종 다양한 형태의 악벽 (惡癖, stable vices)을 가지게 한다. 경주마에서 나타나는 악벽은 어 떤 자극에 대한 반응이거나 혹은 그들이 살고 있는 환경에 적응하기 위해 생긴 습관이다(Cooper,

Corresponding author : Sang Rak Lee, College of Animal Bioscience \& Technology, Konkuk University, 1 Hwayang-dong, Gwangjin-gu, Seoul, 143-701, Korea.

Tel : 02-450-3696, Fax : 02-458-2124, E-mail : leesr@konkuk.ac.kr 
2000).

악벽의 발생원인은 야생상태로 자유롭게 생 활하던 말들이 마방에 갇혀 생활하게 되면서 자유롭게 생활하고 싶다는 욕구와 분명하고 확 실한 것을 좋아하는 말들이 갑자기 낮선 환경 이나 사람이 나타나면 자기에게 해가 되는 일 이 발생할지 모른다는 불안감과 하루 종일 마 방에서 혼자 생활함으로써 생기는 지루함, 동 료와 다른 말들의 행동을 잘 따라서 하는 모방 성과 악벽을 나타나게 하는 미지의 인자가 후 세에 전달되는 유전성, 질병이나 통증 등으로 육체적 컨디션이 나쁘거나 피곤할 때 등이 주 원인이 된다고 한다(한국마사회, 1999b).

악벽은 한번 생기면 고치기가 매우 힘들고 더욱이 경주마에 있어서 악벽은 말 관리를 어 렵게 할 뿐만 아니라 경주능력에도 큰 영향을 미치며 때로는 말의 건강을 해치기도 하기 때 문에 악벽의 발생에는 깊은 주의를 기울여야 하며, 말의 악벽이 대부분 환경적 요인으로부 터 기인하기 때문에 쾌적한 환경을 유지토록 노력하여야 한다. 악벽의 발생원인과 그 대처 방안에 관한 학술적인 연구는 그다지 많지 않 으며 우리나라에서도 약 70 여년의 경마 역사를 가지고 있음에도 불구하고 악벽에 대한 연구는 전혀 이루어져 있지 않다.

이러한 관점에서 본 조사 연구에서는 우선 우리나라에서 관리되고 있는 경주마에서 나타 나는 악벽의 종류와 그 출현빈도를 조사하여 악벽의 개선방안을 모색코자 하였다. 이를 위
하여 현재 서울경마공원에서 관리되고 있는 경 주마를 대상으로 악벽의 출현율을 성별, 나이 별, 마사입사년차별로 나누어 조사하였다.

\section{ㅁ. 재료 및 방법}

\section{1. 공시마필}

본 조사대상의 마필은 한국마사회 서울경마 공원 조교사협회에 2001년 1월 11일부로 마명 이 등록된 1,386 두였으며, 마필의 항목별 분류 는 Table 1 과 같다.

성별로는 암말 726 두, 숫말 364두 및 거세마 296두, 나이별로는 2세에서 11세까지 각각 24 두, 431두, 419두, 294두, 104두, 65두, 33두, 12 두, 1 두 및 3 두였으며, 마방입사년차별로는 1년 차마 520두, 2년차마 442두, 3년차마 258두, 4 년차마 101두, 5년차마 47두, 6년차마 11두, 7 년차 및 8 년차마 3 두, 9년차마가 1 두였다.

\section{2. 마필 관리}

1일 마필관리는 Table 2와 같다. 공시 경주마 들의 하루일과는 놀이운동, 조교, 사료급식, 방 목, 야식으로 비교적 통일되게 관리되고 있었 으며 일과는 각 관리조나 계절에 따라 약간의 차이가 있으며, 경마일에는 마필의 경주 참가 로 인하여 일과가 다소 다르다.

Table 1. Classification of horses investigated in this study

\begin{tabular}{|c|c|c|c|c|c|}
\hline \multicolumn{2}{|c|}{ Sex } & \multicolumn{2}{|c|}{ Age } & \multicolumn{2}{|c|}{ Year of stabling } \\
\hline Female & 726 & 2 & 24 & 1 & 520 \\
\hline Male & 364 & 3 & 431 & 2 & 442 \\
\hline Castrated & 296 & 4 & 419 & 3 & 258 \\
\hline \multirow[t]{8}{*}{ Total } & 1386 & 5 & 294 & 4 & 101 \\
\hline & & 6 & 104 & 5 & 47 \\
\hline & & 7 & 65 & 6 & 11 \\
\hline & & 8 & 33 & 7 & 3 \\
\hline & & 9 & 12 & 8 & 3 \\
\hline & & 10 & 1 & 9 & 1 \\
\hline & & 11 & 3 & Total & 1386 \\
\hline & & Total & 1386 & & \\
\hline
\end{tabular}


Table 2. Daily management schedule for horse

\begin{tabular}{cl}
\hline $\begin{array}{c}\text { Time in } \\
\text { a day }\end{array}$ & \multicolumn{1}{c}{ Schedule } \\
\hline \hline 06:00 & Warming up training, get rid of feces \\
09:00 & Morning feeding \\
10:00 & Grazing, hair care, health care, hoof \\
& care \\
11:30 & Noon feeding \\
$14: 00$ & Grazing and playing exercise \\
16:00 & Evening feeding \\
$21: 00$ & Supplemental feeding \\
\hline
\end{tabular}

\section{3. 급여 사료}

경주마에게 급여하는 사료의 양은 훈련강도 에 따라 급여하는 양을 달리하였는데 주별 일 정에 따라 가벼운 운동을 할 때에는 마필의 체 중 당 건초 $1.0 \sim 2.0 \%$ 와 곡류사료 $0.5 \sim 1.0 \%$ 를 급여하였고 중간정도의 운동을 할 때에는 마필 체중 당 건초 $1.0 \sim 2.0 \%$, 곡류사료 $0.75 ~ 1.5 \%$ 를 급여하였으며, 심한 운동을 할 때에는 마필 체 중 당 건초 $0.75 ~ 1.5 \%$, 곡류사료 1.0 2.0\%를 급 여하였다. Table 3에 경주마의 주별 훈련일정을 나타내었다.

사료급여방법은 하루분의 사료를 3회로 나누 어 급여하였는데 석식의 양을 가장 많이 급여 하였고 조식과 중식의 양은 동일하게 급여하였 으며, 통상 건초를 급여 할 때는 하루 급여량 의 $1 / 4$ 을 각각 아침과 점심에 급여하고 나머지 $1 / 2$ 은 말이 충분한 시간을 가지고 섭취할 수 있는 밤에 급여하였다. 급여 순서는 보통은 곡 류사료를 급여하고 나서 건초를 급여하였다.

4. 경주마 마사
마방의 크기는 $2.8 \mathrm{~m} \times 3.4 \mathrm{~m}$ 였으며 통로는 폭 이 $3.2 \mathrm{~m}$ 였다. 마사의 양쪽 끝 마방은 보호마방 으로 마방벽에 고무판이 부착되어 있었다. 마 방의 출입구는 폭이 $1.2 \mathrm{~m}$ 로 문은 미닫이식으 로 되어 있고 마신봉에는 물통이 걸려 있으며, 출입문옆 벽에는 $2.5 \mathrm{~m}$ 높이에 길이 $130 \mathrm{~cm}$, 굵 기 $5 \mathrm{~mm}$ 정도의 2줄의 쇠고리가 설치되어 있 어서 지름 $50 \mathrm{~cm}$, 높이 $28 \mathrm{~cm}$ 의 FRP나 고무 재 질의 원형 사료통을 매달아 놓고 있었다.

마신봉이 설치되어 있지 않은 마방에는 출입 문에 쇠고리를 설치하여 문을 열었을 때 말이 밖으로 나오지 못하도록 되어 있었고, 그 쇠고 리에 물통이 매달려 있었으며, 배식구를 통하 여 고무재질의 5 각형의 사료통에 사료를 공급 할 수 있도록 되어 있었다.

마방의 바닥은 콘크리트가 깔려 있으며 그 위에 톱밥 등의 깔짚을 깔아주고 있었다.

\section{5. 악벽의 조사방법}

악벽의 조사는 서울경마공원 조교사협회의 52 개 관리조가 관리하는 마필을 대상으로 실시 하였는데, 각 관리조의 조교보를 2000년 12월 20일에 소집하여 악벽별 유형을 설명하고 악벽 조사서를 배부하였으며, 2000년 12월 20일부터 2001년 1월 20일까지 본 연구자가 각 조를 방 문하여 마필관리 담당자를 면담한 후 회수하여 분석하였다.

\section{6. 조사항목}

조사항목은 성별, 연령별, 마사입사년차별의 악벽을 조사하였다.

성별은 암, 수 및 거세마로 구분하였으며 연 령은 한국마사회 규정 (한국마사회규정집, 1999)

Table 3. Weekly training schedule for race horses

\begin{tabular}{cccccccc}
\hline Weeks & Mon & Tue & Wed & Thu & Fri & Sat & Sun \\
\hline \hline 1st & - & Rest & R/W & R/W & T1/2 & T1 & T1,C1/2 \\
2nd & Rest & Rest & T1,C1/2 & T1,C1/2 & T1,C1 & T1,C1 & T1,C1 \\
\multirow{2}{*}{ 3rd } & T1,C1 & \multirow{2}{*}{ Rest } & T1,C1 & T1,C1 & T1,C1 & T1,C1/2 & Race \\
\hline
\end{tabular}

R: Riding exercise, W: Walk, T: Trot, C: Canter, G: Gallop. 
에 의거하여 계산하였다. 마방입사년차의 기준 은 도입일을 기준으로 하여 1 년 미만은 1 년차 로, 2년 미만은 2년차로, 3년 미만은 3년차 등 으로 구분하였다.

\section{7. 악벽의 분류}

악벽은 다음의 총 19 가지 유형별로 분류하여 조사하였다.

즉, 웅벽 (Weaving : 앞발을 벌려 딛고 좌우로 흔드는 버릇), 축벽 (Kicking at walls : 벽을 차는 버릇), 석벽 (Wind-sucking : 끙끙이, 공기를 들 이 마시는 버릇), 앞발로 바닥을 긁는 버릇 (Pawing), 쇠고리를 물고 노는 버릇 (Cribbing with a metal hoop), 후퇴벽 (Stepping backward : 뒷거름 치는 행동), 꼬리를 모서리에 대고 비비 는 행동 (Rubbing tale against wall), 통째로 급하 게 삼키는 버릇 (Swallowing at one gulp), 마방 안에서 빙빙도는 행동 (box-walking), 공격하는 행동 (Biting), 무는 버릇 (Crib biting), 깔짚을 먹 는 버릇 (Bed eating), 사람 기피증 (Refusal to horsekeeper), 이식증 (pica), 앞발을 높이 들어올 리는 버릇 (Rearing : 기립), 물통을 가지고 노는 버릇 (Cribbing with water bucket), 마방에 들어 가지 않으려는 버릇 (Refusal to enter a stable), 두 가지 버릇이 있는 것 (Having 2 type vice), 세 가지 버릇이 있는 것 (Having 3 type vice)으 로 분류하여 조사하였다.

\section{8. 통계처리}

조사된 각 종류별 악벽의 수를 각 항목별 조 사 총 악벽의 수에 대한 백분율을 계산하여 악 벽의 출현율로 나타내었다.

III. 결 과

\section{1. 성별 악벽의 종류별 출현율}

성별 악벽의 출현율은 Table 4와 같다.

총두수 1,386 두 중 숫말의 출현율이 가장 높았으며, 다음으로 거세마, 암말 순으로 조사
되었다. 암, 수 및 거세마 순으로 $3.2 \%$ (23두), $6.0 \%$ (22두) 및 $5.1 \%$ (15두)가 2가지 악벽을 나 타내었고, 3 가지의 악벽을 가진 말은 암, 수 및 거세마 순으로 보면 $0.1 \%$ (1두), $0.3 \%$ (1두) 및 $0.7 \%$ (2두) 순으로 거세마가 높은 출현율을 보 였다.

성별 주요 악벽의 종류별 출현율은 축벽의 출현율이 $5.5 \%$ (76두)로 가장 높게 조사되었는 데 이중 암말의 출현율이 $7.0 \%$ (51두)로 가장 높았으며 거세마 5.4\% (16두), 숫말 $2.5 \%$ (9두) 순으로 나타났다. 다음으로 웅벽 $5.1 \%$ (71두), 무는버릇 $5.1 \%$ (70두)의 순으로 악벽의 출현율 을 보였는데, 웅벽은 거세, 암, 수 순으로 $5.7 \%$, $5.6 \%$ 및 $3.6 \%$ 로 거세마가 가장 높은 출현율을 보였으며, 무는 버릇에서는 수, 거세, 암의 순 으로 숫말이 $12.9 \%$ 로 상당히 높은 출현율을 보 였으며 거세마 $2.7 \%$, 암마 $2.1 \%$ 순으로 조사되 었다. 앞발로 바닥을 긁는 버릇의 출현율은 전 체가 $4.8 \%$ (66두)로 거세마, 암말, 숫말의 순으 로 각각 $6.1 \%, 4.7 \%, 3.8 \%$ 로 나타났다. 석벽의 총 출현율은 $4.3 \%$ (60두)로 거세마, 암마, 수마 의 순으로 $7.1 \%, 4.4 \%, 1.9 \%$ 였고, 쇠고리를 물 고노는 버릇은 $1.9 \%$ (27두)였다. 깔짚을 먹는 버릇은 $1.9 \%$ (26두)로 조사되었고, 마방에서 빙 빙 도는 행동은 $1.8 \%$ (25두)였다. 공격하는 행 동은 $1.6 \%$ (22두)로, 사람기피증 $1.2 \%$ (17두), 기 립벽 1.2\%(16두), 이식증 $0.9 \%$ (12두), 후퇴벽 $0.9 \%$ (13두), 통째로 급하게 삼키는 버릇 $0.8 \%$ (11두), 꼬리를 비비는 행동 $0.7 \%$ (10두), 물통을 가지고 노는 버릇 $0.1 \%$ (1두), 마방에 들어가지 않으려는 버릇이 $0.1 \%$ (1두) 순으로 각각 조사 되었다.

\section{2. 나이별 악벽의 종류별 출현율}

\author{
나이별 악벽의 종류별 출현율은 Table 5와 \\ 같다.
}

나이별 악벽의 총 출현율은 2세마가 $50 \%, 6$ 세마가 $44.2 \%, 4$ 세마가 $43 \%, 5$ 세마가 $38.1 \%, 3$ 세마가 $33.4 \%$ 순으로 나타났으며, 7세 이후는 악벽을 나타낸 말이 $26.3 \%$ 로 비교적 적게 나타 났다. 2 가지 악벽을 보면 총 $4.3 \%$ (60두)의 출 
Table 4. Appearance rate of stable vice of horses according to sex

\begin{tabular}{lrrrr}
\hline \multirow{2}{*}{ Item } & \multicolumn{3}{c}{ Sex } \\
\cline { 2 - 5 } & Female & Male & Castrated & Total \\
\hline \hline Total investigated horse, head & 726 & 364 & 296 & 1386 \\
Total count of vice, count & 257 & 148 & 119 & 524 \\
Having 2 type vice, head ${ }^{1)}$ & 23 & 22 & 15 & 60 \\
Having 3 type vice, head ${ }^{1)}$ & 1 & 1 & 2 & 4 \\
\hline Appearance rate, \% & & & \\
Total & 35.4 & 40.7 & 40.2 & 37.8 \\
Weaving & 5.6 & 3.6 & 5.7 & 5.1 \\
Kicking at wall & 7.0 & 2.5 & 5.4 & 5.5 \\
Wind-sucking & 4.4 & 1.9 & 7.1 & 4.3 \\
Pawing & 4.7 & 3.8 & 6.1 & 4.8 \\
Cribbing with a metal hoop & 1.9 & 2.2 & 1.7 & 1.9 \\
Stepping backward & 1.1 & 0.3 & 1.4 & 0.9 \\
Rubbing tale against wall & 1.0 & 0.3 & 0.7 & 0.7 \\
Swallowing at one gulp & 0.1 & 1.9 & 1.0 & 0.8 \\
Box-walking & 1.9 & 1.9 & 1.4 & 1.8 \\
Biting & 1.1 & 2.5 & 1.7 & 1.6 \\
Crib biting & 2.1 & 12.9 & 2.7 & 5.1 \\
Bed eating & 1.1 & 3.0 & 2.4 & 1.9 \\
Refusal to horsekeeper & 1.8 & 0.3 & 1.0 & 1.2 \\
Pica & 0.6 & 1.6 & 0.7 & 0.9 \\
Rearing & 0.7 & 1.9 & 1.4 & 1.2 \\
Cribbing with water bucket & 0.1 & 0.0 & 0.0 & 0.1 \\
Refusal to enter a stable & 0.1 & 0.0 & 0.0 & 0.1 \\
Having 2 type vice ${ }^{1)}$ & 3.2 & 6.0 & 5.1 & 4.3 \\
Having 3 type vice ${ }^{1)}$ & 0.1 & 0.3 & 0.7 & 0.3 \\
\hline
\end{tabular}

1) Having 2 or 3 independent vice in one horse.

현율을 보였으며 2세마가 8.3\%(2두), 4세마가 $5.3 \%$ (22두), 6세마 4.8\%(5두), 3세마 4.2\% (18 두) 5 세마 $4.1 \%$ (12두) 순이었고 3 가지 악벽을 보인 말들은 $0.3 \%$ (4두) 조사되었다.

악벽의 종류별 출현율을 보면 2세마에서는 총 $50 \%$ (12두)의 출현율을 보였는데 축벽, 석 벽, 앞발로 바닥을 긁는 버릇, 무는 버릇들이 8.3\%로 가장 높았고, 3세마에서는 $33.4 \%$ (144 두)의 출현율로 앞발로 바닥을 긁는 버릇이 $4.9 \%$ 였고, 4 세마에서는 $43 \%$ (180두)로 축벽 (6.4 $\%)$ 과 웅벽 $(6.0 \%)$, 무는 버릇 $(6.0 \%)$ 이 높은 출 현율을 보였으며 5세마에서는 $38.1 \%$ (112두)로 축벽 (6.8\%)과 무는 버릇 (6.8\%), 웅벽 (6.5\%) 순 으로, 6세마에서는 $44.2 \%$ (46두)로 무는 버릇과 웅벽이 (8.7\%), 축벽 $(7.7 \%)$ 등의 출현율이 높게
조사되었다.

\section{3. 마방입사년차별 악벽의 종류별 출현율}

마방입사년차별 악벽의 종류별 출현율은 Table 6 과 같다.

총 1,386 의 조사마중 마방입사년차는 1 년차 에서 9년차까지 조사되었는데 1년차는 520두 중 $35.2 \%$ (183두), 2년차는 442두 중 41\%(181 두), 3년차는 258두 중 39.1\%(101두), 4년차는 101 두 중 $40.6 \%$ (41두), 5년차 이상의 말은 65 두 중에서 $27.7 \%$ (18두)로 조사되었고, 2가지 악벽은 1 년차가 $4.6 \%, 2$ 년차가 $5.0 \%, 3$ 년차는 $4.3 \%, 4$ 년차는 $2.0 \%, 5$ 년차 이상의 말에서는 $1.5 \%$ 로 조사되었다. 
Table 5. Appearance rate of stable vice of horses according to age

\begin{tabular}{|c|c|c|c|c|c|c|c|c|}
\hline \multirow{2}{*}{ Item } & \multicolumn{8}{|c|}{ Age } \\
\hline & 2 & 3 & 4 & 5 & 6 & 7 & $>8$ & Total \\
\hline Total investigated horse, head & 24 & 431 & 419 & 294 & 104 & 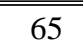 & 49 & 1386 \\
\hline Total count of vice, count & 12 & 144 & 180 & 112 & 46 & 15 & 15 & 524 \\
\hline Having 2 type vice, head ${ }^{1)}$ & 2 & 18 & 22 & 12 & 5 & 1 & 0 & 60 \\
\hline Having 3 type vice, head ${ }^{1)}$ & 0 & 0 & 2 & 1 & 0 & 1 & 0 & 4 \\
\hline \multicolumn{9}{|l|}{ Appearance rate, \% } \\
\hline Total & 50.0 & 33.4 & 43.0 & 38.1 & 44.2 & 23.1 & 30.6 & 37.8 \\
\hline Weaving & 0.0 & 2.6 & 6.0 & 6.5 & 8.7 & 7.7 & 4.1 & 5.1 \\
\hline Kicking at wall & 8.3 & 3.2 & 6.4 & 6.8 & 7.7 & 3.1 & 6.1 & 5.5 \\
\hline Wind-sucking & 8.3 & 3.0 & 4.8 & 5.8 & 3.8 & 4.6 & 2.0 & 4.3 \\
\hline Pawing & 8.3 & 4.9 & 5.0 & 4.4 & 4.8 & 0.0 & 8.2 & 4.8 \\
\hline Cribbing with a metal hoop & 4.2 & 2.3 & 1.9 & 1.4 & 1.0 & 3.1 & 2.0 & 1.9 \\
\hline Stepping backward & 0.0 & 1.4 & 1.4 & 0.3 & 0.0 & 0.0 & 0.0 & 0.9 \\
\hline Rubbing tale against wall & 4.2 & 0.7 & 0.5 & 0.7 & 0.0 & 3.1 & 0.0 & 0.7 \\
\hline Swallowing at one gulp & 0.0 & 1.6 & 0.7 & 0.0 & 1.0 & 0.0 & 0.0 & 0.8 \\
\hline Box-walking & 0.0 & 2.3 & 2.1 & 1.0 & 2.9 & 0.0 & 0.0 & 1.8 \\
\hline Biting & 0.0 & 1.9 & 3.3 & 0.0 & 0.0 & 0.0 & 0.0 & 1.6 \\
\hline Crib biting & 8.3 & 3.2 & 6.0 & 6.8 & 8.7 & 0.0 & 0.0 & 5.1 \\
\hline Bed eating & 4.2 & 2.6 & 1.4 & 1.4 & 1.9 & 0.0 & 4.1 & 1.9 \\
\hline Refusal to horsekeeper & 0.0 & 1.2 & 1.2 & 1.0 & 1.9 & 1.5 & 2.0 & 1.2 \\
\hline Pica & 4.2 & 1.2 & 0.5 & 0.7 & 1.0 & 0.0 & 2.0 & 0.9 \\
\hline Rearing & 0.0 & 1.4 & 1.4 & 1.0 & 1.0 & 0.0 & 0.0 & 1.2 \\
\hline Cribbing with water bucket & 0.0 & 0.0 & 0.2 & 0.0 & 0.0 & 0.0 & 0.0 & 0.1 \\
\hline Refusal to enter a stable & 0.0 & 0.0 & 0.0 & 0.3 & 0.0 & 0.0 & 0.0 & 0.1 \\
\hline Having 2 type vice ${ }^{1)}$ & 8.3 & 4.2 & 5.3 & 4.1 & 4.8 & 1.5 & 0.0 & 4.3 \\
\hline Having 3 type vice ${ }^{1)}$ & 0.0 & 0.0 & 0.5 & 0.3 & 0.0 & 1.5 & 0.0 & 0.3 \\
\hline
\end{tabular}

1) Having 2 or 3 independent vice in one horse.

악벽의 종류별 출현율을 보면 1 년차는 앞발 로 바닥을 긁는 버릇, 석벽, 축벽, 무는 버릇 순으로 $6.0 \%, 3.8 \%, 3.7 \%, 3.3 \%$ 나타났고, 2년 차는 축벽, 웅벽, 무는 버릇, 석벽, 앞발로 바닥 을 긁는 버릇 순으로 $7.0 \%, 6.3 \%, 6.1 \%, 4.8 \%$, $4.1 \%, 3$ 년차는 무는 버릇, 축벽, 웅벽, 석벽 순 으로 $7.4 \%, 7.0 \%, 6.6 \%, 5.0 \%$ 이고 4년차는 웅 벽, 축벽, 석벽, 앞발로 바닥을 긁는 버릇, 무는 버릇 순으로 $6.9 \%, 5.9 \%, 5.0 \%, 5.0 \%, 5.0 \%$, 5년 차 이상의 말에서는 웅벽 $9.2 \%$, 축벽, 앞발로 바닥을 긁는 버릇, 무는 버릇이 각각 $3.1 \%$ 를 나타내었다.

\section{IV. 고 찰}

본 조사연구에서는 한국마사공원에서 관리되 고 있는 경주마의 $37.8 \%$ 가 악벽을 가지고 있는 것으로 나타났다.

McGreevy 등 (1995a)의 연구에서는 상대적으 로 많은 시간을 마사내에서 보내는 조교마에서 총 744 두 중 $32.5 \%$ 에서 이상행동이 출현하였으 며, 마사 밖에서 지내는 시간이 많은 역마의 경우는 총 211 두 중에서 $19 \%$ 의 말에서 이상행 동 출현율을 보였다고 보고하고 있어서 본 조 사연구보다 낮은 출현율을 보였다. 이는 마사 
Table 6. Appearance rate of stable vice of horses according to year of stabling

\begin{tabular}{|c|c|c|c|c|c|c|}
\hline \multirow{2}{*}{ Item } & \multicolumn{6}{|c|}{ Year of stabling } \\
\hline & 1 & 2 & 3 & 4 & $>5$ & Tota \\
\hline Total investigated horse, head & 520 & 442 & 258 & 101 & 65 & 1386 \\
\hline Total count of vice, count & 183 & 181 & 101 & 41 & 18 & 524 \\
\hline Having 2 type vice, head ${ }^{1)}$ & 24 & 22 & 11 & 2 & 1 & 60 \\
\hline Having 3 type vice, head ${ }^{1)}$ & 2 & 0 & 1 & 0 & 1 & 4 \\
\hline \multicolumn{7}{|l|}{ Appearance rate, \% } \\
\hline Total & 35.2 & 41.0 & 39.1 & 40.6 & 27.7 & 37.8 \\
\hline Weaving & 2.5 & 6.3 & 6.6 & 6.9 & 9.2 & 5.1 \\
\hline Kicking at wall & 3.7 & 7.0 & 7.0 & 5.9 & 3.1 & 5.5 \\
\hline Wind-sucking & 3.8 & 4.8 & 5.0 & 5.0 & 1.5 & 4.3 \\
\hline Pawing & 6.0 & 4.1 & 3.9 & 5.0 & 3.1 & 4.8 \\
\hline Cribbing with a metal hoop & 2.1 & 1.6 & 1.9 & 3.0 & 1.5 & 1.9 \\
\hline Stepping backward & 1.9 & 0.5 & 0.4 & 0.0 & 0.0 & 0.9 \\
\hline Rubbing tale against wall & 0.8 & 0.7 & 0.4 & 1.0 & 1.5 & 0.7 \\
\hline Swallowing at one gulp & 1.3 & 0.7 & 0.0 & 1.0 & 0.0 & 0.8 \\
\hline Box-walking & 1.9 & 1.8 & 1.9 & 2.0 & 0.0 & 1.8 \\
\hline Biting & 1.2 & 3.2 & 0.4 & 1.0 & 0.0 & 1.6 \\
\hline Crib biting & 3.3 & 6.1 & 7.4 & 5.0 & 3.1 & 5.1 \\
\hline Bed eating & 2.3 & 2.0 & 0.8 & 2.0 & 1.5 & 1.9 \\
\hline Refusal to horsekeeper & 1.5 & 0.7 & 1.6 & 1.0 & 1.5 & 1.2 \\
\hline Pica & 1.2 & 0.2 & 1.2 & 1.0 & 1.5 & 0.9 \\
\hline Rearing & 1.7 & 1.1 & 0.4 & 1.0 & 0.0 & 1.2 \\
\hline Cribbing with water bucket & 0.0 & 0.0 & 0.4 & 0.0 & 0.0 & 0.1 \\
\hline Refusal to enter a stable & 0.0 & 0.2 & 0.0 & 0.0 & 0.0 & 0.1 \\
\hline Having 2 type vice ${ }^{1)}$ & 4.6 & 5.0 & 4.3 & 2.0 & 0.0 & 4.3 \\
\hline Having 3 type vice ${ }^{1)}$ & 0.4 & 0.0 & 0.4 & 0.0 & 0.0 & 0.3 \\
\hline
\end{tabular}

1) Having 2 or 3 independent vice in one horse.

내에서 보내는 시간에 있어서의 차이가 한 원 인이 될 수 있겠지만 마사나 마필관리의 차이 에서도 나타날 수 있을 것이다. McGreevy 등 (1995b)의 연구에서도 조교마와 역마에서의 악 벽 출현율의 차이가 마사 내에서 보내는 시간 의 차이였다고 단정 짓고 있다.

McGreevy 등 (1995b)의 경주마를 대상으로 한 연구에서는 말들에게 상대적으로 많은 양의 조사료를 공급함으로써 악벽의 출현율을 줄였 다고 보고하고 있다. 이는 우선 많은 양의 조 사료를 공급함으로써 말들에게 상대적으로 사 료의 섭취에 많은 시간을 보내도록 하여 말이
심심하지 않게 하는 효과가 영향을 미친 것으 로 해석된다.

많은 연구자가 말에서의 악벽은 대부분 말이 마사내에서 권태를 이기기 위한 수단으로 보고 있다 (Marthe, 1987). 따라서 마사내에서 말들이 따분하지 않도록 하는 것이 악벽을 막는 좋은 수단으로 보인다.

일반적으로 경주마들은 육성기에는 방목 등 을 주 일과로 삼았으나 개별 마방에서 정해진 일과를 보내면서 방목 중에 보였던 행동을 은 연중에 나타내기도 한다. 이것이 궁극적으로는 하나의 습관이 되어버리는 것이다. 
또한 적절치 못한 사육환경도 이들에게 악벽 을 가지게 한다(Cooper와 Mason, 1998). 관리자 나 일과가 이들에게 스트레스로 작용할 경우 악벽이 나타난다.

마사나 마방의 구조가 악벽의 출현율에 영향 을 미친다.

McDonald (2001)의 연구에 따르면 마방의 크 기와 모양에 따라, 깔짚의 종류에 따라서도 악 벽의 출현율이 다르다고 하며, 사조나 물통의 위치와 형태도 영향을 미친다고 한다.

본 연구에서도 악벽의 출현율을 다양한 요인 에서 분석코자 하였으나 조사특성상 반복을 두 지 못하여 통계적인 검정을 하지 못하였다. 이 상의 조사결과에서 우리나라에서 관리되고 있 는 경주마에서 비교적 높은 악벽의 출현율이 나타나 마사시설 개선과 관리기술의 향상이 요 구되는 것으로 사료되며 추후 악벽을 나타내는 다양한 요인별로 조사할 필요가 있다고 생각된 다.

\section{V. 요 약}

본 조사연구에서는 우리나라에서 관리되고 있 는 경주마에서 나타나는 악벽의 종류와 그 출현 빈도를 조사하기 위하여 현재 서울경마공원에서 관리되고 있는 경주마 총 1,386 두를 대상으로 마사내에서의 주요 악벽의 출현율을 성별, 나이 별, 마사입사년차별로 나누어 조사하였다.

경주마의 악벽은 총 조사두수 1,386 두 중 $37.8 \%$ 인 524 두가 가지고 있었다. 성별에서는 숫말에서 가장 높은 $40.7 \%$ 의 출현율을 보였고, 나이별에서는 2세, 6세 및 4세마에서 각각 $50.0 \%, 44.2 \%$ 및 43\%로 높은 출현율을 보였고, 마방입사년차별에서는 2년차, 4년차 및 3년차 에서 $41 \%, 40.6 \%$ 및 $39.1 \%$ 로 높게 나타났다.

악벽별로는 성별에서 암말은 축벽에서 $7.0 \%$ 로 가장 높았고, 숫말에서는 무는 버릇이 12.9 $\%$, 거세마에서는 웅벽이 $5.7 \%$ 로 가장 높은 출 현율을 보였다.

나이별로는 2 세마에서 축벽이 $8.3 \%$, 석벽이 $8.3 \%$, 앞발로 바닥을 긁는 버릇이 $6.1 \%, 3$ 세마
에서는 앞발로 바닥을 긁는 버릇이 $4.9 \%, 4$ 세 마는 축벽이 $6.4 \%, 5$ 세마는 축벽과 무는 버릇 이 $6.8 \%, 6$ 세마에서는 웅벽과 무는 버릇이 8.7 $\%$ 로 높게 나타났다.

마방입사년차별에서는 1 년차에서는 앞발로 바닥을 긁는 버릇이 $6.0 \%, 2$ 년차에서는 축벽이 $7.0 \%, 3$ 년차에서는 무는 버릇이 $7.4 \%, 4$ 년차와 5 년차 이상의 말에서는 웅벽이 각각 $6.9 \%$ 및 $9.2 \%$ 로 높게 조사되었다.

\section{VI. 인 용 문 헌}

1. Brega, J. 1993. The Horse General Management, p124-142. J. A. Allen \& Company Ltd.

2. Cooper J. J. and Mason, G. J. 1998. The identification of abnormal behaviour and behaviour problems in stabled horses and their relationship to horse : a comparative review. Equine Vet. J. 27 : 5-9.

3. Cooper, J. 2001. Is abnormal behaviour a behavioral problem?. Animal Behaviour Research Group, Department of Zoology, University of Oxford.

4. Marthe, K. W. 1987. The behaviour of horses, p189-215. J. A. Allen \& Company Ltd.

5. McDonald, L. 2001. Increasing opertunities for social interaction rduce stereotypic weaving in stabled horses. BSc thesis. Montfort Univ.

6. McGreevy, P. D., Richardson, J. D., Nicol, C. J. and Lane, J. G. 1995a. A radiographic and endoscopic study of horses performing an oral stereotypy. Equine Vet. J. 27:92-95.

7. McGreevy, P. D., Cripps, P. J., French, N. P., Green, L. E. and Nicol, C. J. 1995b. Management factors associated with stereotypic and redirected behaviour in the throughbred horse. Equine Vet. J. 27:86-91.

8. 한국마사회, 1999a. 규정집,

9. 한국마사회, 1999b. 말과 목장.

(접수일자 : 2008. 1. 2. / 수정일자: 2008. 12. 5. / 채택일자 : 2008. 12. 18.) 